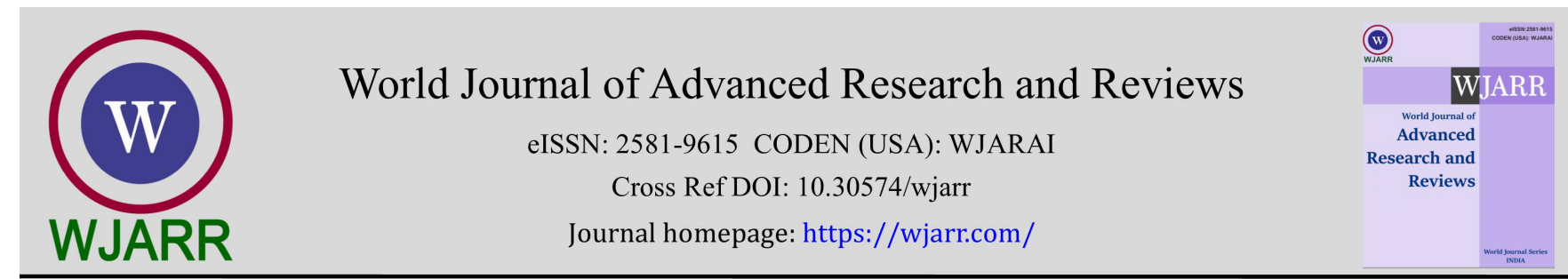

(RESEARCH ARTICLE)

\title{
Identification of polyester toys dust mites
}

\author{
Guillermo Muñoz Zurita ${ }^{1,{ }^{*}}$ and Silvia Bocanegra Carrillo ${ }^{2}$ \\ ${ }^{1}$ Faculty of Medicine Benemérita Universidad Autónoma de Puebla (FMBUAP), Mexico. \\ 2 Emiliano Zapata High School Benemérita Autonomous University of Puebla, Mexico.
}

World Journal of Advanced Research and Reviews, 2021, 10(02), 203-205

Publication history: Received on 05 April 2021; revised on 07 May 2021; accepted on 09 May 2021

Article DOI: https://doi.org/10.30574/wjarr.2021.10.2.0212

\begin{abstract}
The importance of the surrounding environment and ecological microcosms to determine identification of mites in this particular polyester toys because these objects have the necessary criteria survival and reproduction of different kinds of mites, most people have them and are propitious source so that people can develop atopic vulnerably or exacerbate allergic reactions. Objective: To identify dust mites on polyester toys. Materials and methods. This work is descriptive, cross-section. Period: January to February 2021. Study population: 55 toys Polyester, 51 samples were observed under a microscope Karl Zeiss stereoscope, we used the method of Hart and Fain. Results. Mite Dermatophagoides pteronyssinus was the most identified, appeared in 30 (58.8\%) positive samples.
\end{abstract}

Keywords: Mites; polyester toys

\section{Introduction}

The etiology of respiratory allergies has been a subject of interest and study for many centuries and, as early as 1698 , John Floyer showed that house dust was one of the main factors involved in this problem. However, the presence of allergens in house dust could not be confirmed with skin tests until the early 20 th century. ${ }^{1-5}$ The role of mites in dust allergy was first suggested by H. Dekker in 1928, after finding a large number of unidentified mites in house dust, especially in mattresses, and observing that allergic patients had fewer symptoms in an environment without mites. ${ }^{6}$ This hypothesis was confirmed in 1964, when a group of researchers showed that some mites that lived in house dust, not specifically identified but belonging to the genus Dermatophagoides wogdanov 1864, caused respiratory allergy.7 They found that these mites were present in most of those studied in Europe and that their extracts produced, in asthmatic homes, skin reactions similar to those produced by dust. ${ }^{8-11}$ The most prevalent allergy mite species in most countries is D. pteronyssinus, while D. farinae and E. maynei may be present in varying amounts, depending on the climate. The species D. pteronyssinus and D. farinae account for more than $90 \%$ of the mites found in samples of house dust, and are the main cause of respiratory allergy. ${ }^{12-13}$ Certain species of mites belonging to the families Acaridae and Glycyphagidae are found occasionally in house dust, although its main habitat is stored products. Their importance lies not only in the economic aspect, but in that they are also implicated in the etiology of respiratory diseases in people who work with stored products and are a source of household allergens. 8,14 Several studies show how in environments without mites, allergic patients have less symptoms. These results have suggested that one of the first forms of treatment for these patients should be to reduce exposure to mites and their allergens. ${ }^{15}$ With the aforementioned antecedents and observing the importance of the environmental environment and its ecological microcosm, we set out to This study determines the identification of mites in polyester toys since these objects meet all the necessary criteria of ecology for the survival and reproduction of the various genera of mites during the period from January to February 2021.

\footnotetext{
* Corresponding author: Guillermo Muñoz Zurita

Facultad de Medicina Benemérita Universidad Autónoma de Puebla (FMBUAP). 


\section{Material and methods}

The present work is descriptive type, cross section. Period: January to February 2021. Study population: 55 polyester toys requested from students of the BUAP School of Medicine. Dust and fiber samples were collected using brushes and scissors, which were deposited in sterile bottles. The students were asked about factors close to the study objects, such as: number of people living in the house, proximity of the object with animals, presence and proximity to windows, people suffering from respiratory or allergic infections, presence of carpets. Of the collected samples, 4 were discarded because they did not meet the inclusion criteria. The samples were then placed in Petri dishes, 51 samples were observed under the Karl Zeiss stereoscope microscope. The flotation method described by Hart and Fain was used to extract mites. ${ }^{15}$

\section{Results}

Of the 51 samples analyzed, 26 (50.9\%) identified at least one type of mite. The number of mites found was very varied, the average being 9, the minimum 3. Dermatophagoides pteronyssinus was the most identified mite, it appeared in 30 (58.8\%) of the positive samples, followed by Glycyphagus domesticus (42.2\%) and Dermatophagoides farinae (34.6\%), the least found species were Tyrophagus putrescentiae (11.3\%). Of the study objects with positive dust samples, 41 $(80.3 \%)$ showed connotation with domestic animals; 20 (39.2\%) association with carpets and/or rugs; In 23 (45\%) samples, a history of coexistence with people with respiratory infections or allergic conditions was detected, 10 (19.6\%) toys were located in houses that had no windows and $36(70.5 \%)$ polyester objects were owned by people who they lived in overcrowding.

\section{Discussion}

In our study we pay attention to the fact that there is a high prevalence of dust mites in polyester toys, probably due to the ecological conditions they provide due to the constitution of their manufacturing materials, which denotes the high risk to which these would be subjected. People from contracting diseases caused by mites such as asthma, allergic rhinitis, rhinoconjunctivitis. ${ }^{8-11}$ This may raise the level of justifying future work on the prevalence of these diseases in vulnerable groups. Dermatophagoides pteronyssinus has been described as the main dust mite in numerous studies; 2,6,12,15 In our project we corroborate this evidence since (58.8\%) of the positive samples for the aforementioned mite, we also check what the bibliographic sources refer to when naming Glycyphagus domesticus as the second place in identification, since in In our report, we identified it in (42.2\%) of the samples and correlated it with the presence of domestic animals. ${ }^{6}$ This work also determines the prevalent association between the presence of dust mites and the presence of animals, in addition to showing their presence in carpets, rugs and lack of ventilation.

\section{Conclusion}

There is a high prevalence of dust mites collected on polyester toys. Dermatophagoides pteronyssinus was the most isolated mite, so it is recommended to avoid exposure of these game objects with domestic animals and overcrowding. Based on the results obtained, we conclude that the presence of carpets, papers as well as the lack of ventilation are transcendent risk factors and that is why it is recommended to avoid.

\section{Compliance with ethical standards}

\section{Disclosure of conflict of interest}

Authors declare that there is no conflict of interest.

\section{References}

[1] Floyer JA. Treatise of the asthma. R. Londres: Wilkin. 1698.

[2] Arlian LG, Rapp CM, Ahmed SG. Development of Dermatophagoides pteronyssinus. Journal of Medical Entomology. 1990; 27: 1035-40.

[3] Colloff MJ. House dust mites (II). Chemical control. Pesticide Outlook. 1990; 1: 3-8.

[4] De la Fuente J.A. Zoología de artrópodos. Madrid: Interamericana. 1994. 
[5] Eraso E. Estudio de la expresión de los componentes alergénicos en cultivos de ácaros del género Dermatophagoides Bogdanov. 1864.

[6] Fain AN. Description de Dermatophagoides pteronyssinus. Importance de cet acarien en pathologie humaine. Acarología. 1966; 8: 302-27.

[7] Le Mao J, Pauli G, Hoyet C, Bischoff E, Schirmacher W, David B. Relationship between mite allergenicity and guanine content in house dust samples. Mite allergy, a world-wide problem. 1987; 1- 2: 65-6.

[8] Platts MTAE, Chapman MD. Dust mites: immunology, allergic disease and enviromental control. Journal of Allergy and Clinical Immunology. 1987; 80: 755-75.

[9] Platts MTAE, De Weck AL. Dust mite allergens and asthma: a worldwide problem. International Workshop Report. Bulletin of the World Health Organization. 1988; 66(6): 769-80.

[10] Platts MTAE, Thomas WR, Aalberse RC, Vervloet D, Chapman MD. Dust mite allergens and asthma. UCB Institute of Allergy (Bruselas). 1991; 11-29.

[11] Platts MTAE, Thomas WR, Aalberse RC, Vervloet D, Chapman MD. Dust mite allergens and asthma: report of a Second International Workshop. Journal of Allergy and Clinical Immunology. 1992; 89: 1046-60.

[12] Voorhorst R, Spieksma FT, Varekamp H. House-dust atopy and the house-dust mite Dermatophagoides pteronyssinus (Trouessart 1897). House-dust atopy and the house-dust mite Dermatophagoides pteronyssinus (Trouessart 1897).1969.

[13] Voorhorst R, Spieksma-Boezeman MIA, Spieksma FTM. Allergie asthma. 1964; 10: 329-34.

[14] Juarez M. Lopez A. Paz M, Galindo A, Papaqui S. Correlación entre prueba cutánea para Dermatophagoides pteronyssinus y Dermatophagoides farinae en pacientes alérgicos del Hospital universitario de Puebla. Revista de Alergia, Asma e Inmunología Pediátricas. 2000; 9 (3): 82-5.

[15] Arias J, García J. Sensibilización cutánea e identificación de ácaros en las viviendas de una población de alérgicos en la provincia de Huelva. Alergia e Inmunología Clínica. 2002; 17: 61-8. 